\title{
Bzmaps: aplicativo desenvolvido para realização de estudos de gerenciamento de áreas de risco à inundação
}

\author{
Bzmaps: application developed for making studies of management of risk \\ to flood areas
}

\author{
Bruno Zucuni Prina'; Romario Trentin"
}

RESUMO

Inúmeros assuntos que estão em destaque atualmente, tanto na mídia como na comunidade científica referem-se aos desastres naturais, com foco às inundações urbanas. Assim sendo, esse trabalho tem o objetivo de apresentar um aplicativo, denominado como BZMAPS, que realiza a síntese de informações acerca do mapeamento de áreas de risco à inundação. Assim, dividiram-se as etapas metodológicas junto a construção das bases cartográficas, organização do banco de dados, sistematização do aplicativo e análise dos dados. Com a utilização do aplicativo é possível dispor de dados organizados e sintetizados, podendo ser realizado consultas textuais ou numéricas dos dados armazenados. Além disso, a partir das seleções de informações, é possível realizar análises junto ao Google Earth. Dessa forma, verifica-se a importância do BZMAPS dentro da análise de áreas de risco à inundação, sendo uma ferramenta de grande importância para o gerenciamento urbano, podendo ser amplamente utilizada dentro de órgãos públicos.

Palavras-chave: Geoprocessamento; Jaguari; Programação; Visual Basic 6

\section{ABSTRACT}

Several papers that are with great importance, currently, in the media and in the scientific community refers to natural disasters focusing on urban flooding. Therefore, this paper aims to present an application, named as BZMAPS. The app realize the information synthesis about mapping of risk areas to flood. So, methodological steps have been divided into: construction of cartographic bases, organization of the database, building application and data analysis. Using the application it is possible get organized data and synthesized, and can be constructed textual or numerical analysis of the data stored. Moreover, from the information selections, you can perform analyzes with Google Earth. Thus, it is verified the importance of BZMAPS in the analysis of the flood risk areas, it is a very important tool for urban management, it can be widely used in government agencies.

Keywords: Geoprocessing; Jaguari; Programming; Visual Basic 6

'Doutor em Geografia UFSM, Tecnólogo em Geoprocessamento E-mail: brunozprina@gmail.com ORCID: https://orcid.org/0000-00027873-5440

"Profo Dr. em Geografia da Universidade Federal de Santa Maria (UFSM) E-mail: romario.trentin@gmail.com ORCID: https://orcid.org/0000-0002-0615-2801 


\section{INTRODUÇÃO}

Dentro das reportagens e publicações da mídia e da comunidade científica, um dos assuntos que estão em grande destaque, principalmente nos últimos anos, referese aos desastres naturais, e, dentro dessa área, as inundações destacam-se como sendo o tipo de evento mais frequente. Corroborando com o exposto, Kron (2002) salienta que as inundações é o tipo de evento, desastroso, que abrange o maior número de pessoas entre os desabrigados/envolvidos.

Esses acontecimentos sobrelevaram, referente as preocupações e perdas (materiais ou não), principalmente nas últimas décadas, onde o processo de urbanização cresceu de forma desordenada, agravando uma série de problemas sociais dentro das cidades, principalmente nas maiores metrópoles. Assim, com um maior número de construções, calçadas, arruamentos, etc. sobre o solo exposto, há a minimização dos processos de infiltração da água no solo, e, em épocas de precipitações intensas, por consequência, há o aumento do escoamento superficial, sobrelevando, assim, o volume dos rios, inundando áreas ribeirinhas.

Dentro dessa preocupação central, o referido trabalho enfatiza uma pesquisa acerca do gerenciamento de informações a serem utilizadas no mapeamento de áreas de risco, com o desenvolvimento de um aplicativo, denominado BZMAPS. Para exemplificar a utilização da referida ferramenta, utilizar-se-á, como recorte espacial, o perímetro urbano do município de Jaguari, localizado no centro-oeste do estado do Rio Grande do Sul (RS), dentro da microrregião de Santa Maria.

Para o entendimento desse trabalho deve-se de haver a fundamentação teórica de alguns conceitos intrínsecos as questões metodológicas a serem aqui implantadas. Assim sendo, haverá uma breve definição dos vocábulos suscetibilidade, perigo, vulnerabilidade (e suas variáveis) e risco. As referidas variáveis precisam ser definidas, a fim de entender e diferenciá-las, pois, cada uma possui seu próprio significado.

A terminologia suscetibilidade pode ser definida como sendo o local onde, de fato, há a incidência do evento, e, sua caracterização, depende exclusivamente da análise de cada lugar. Ribeiro e Lima (2011) destacam que a previsão e o mapeamento dos locais com maiores proporções suscetíveis à ocorrência de inundações são essenciais para a caracterização da superfície 
A nomenclatura perigo, também conhecida como hazard (do inglês), conforme orientações de Magnanelli (2012), pode ser definida como uma fonte ou situação potencial de causar alguma lesão ou doença, danos ao meio ambiente, bem como a combinação dos dois.

Ainda, é importante referenciar a definição de vulnerabilidade. Ayala-Carcedo (2000) define-a como sendo uma variável que está atrelada a intensidade de um evento perigoso. Assim, a partir dessa ideia, Santos (2007) ressalva que a vulnerabilidade, para ser mapeada, necessita de uma análise referente ao grau de desenvolvimento (pobreza) de uma determinada população. Dessa forma, inúmeras são as variáveis que podem estar atreladas às características de um determinado local para defini-la, como por exemplo o tipo das construções, o padrão das residências, entre outros.

Por fim, destaca-se, o conceito de risco. Castro (2000) salienta que a concepção que possui uma maior homogeneidade entre os pesquisadores, é definindo risco como sendo o perigo que se ocorre, ou como a probabilidade de que aconteça um determinado evento perigoso. Já Kron (2002) preconiza que na comunidade científica, a definição de maior aceitação, a respeito do risco, é com a caracterização do conceito como um produto do perigo, junto as suas consequências.

Após o entendimento de algumas questões conceituais, as quais são tratadas no presente trabalho, cabe ressaltar que o problema dessa pesquisa está contido na resolução da seguinte questão: "como realizar uma síntese acerca do mapeamento de áreas de risco à inundação, e, dessa forma desenvolver uma ferramenta útil no gerenciamento dos dados?"

Justifica-se, desse modo, entender que com a utilização do aplicativo BZMAPS será possível dispor de uma metodologia eficiente para a organização dos dados cadastrais, ter objetividade na busca pelas informações, dispor de uma ferramenta com um alto grau de síntese dos dados, porém, sem perda de eficiência. $E$, toda essa análise, poderá ser facilitada às pessoas que dispuserem dessa ferramenta, como por exemplo, o poder público, sendo de grande auxílio no gerenciamento das informações e na tomada de decisões. 
O objetivo geral do trabalho é o de organizar uma ferramenta de síntese de informações acerca do mapeamento das áreas de risco, incluindo objetividade e eficiência na análise dos dados, facilitando o gerenciamento e tomada de decisões. Especificamente tem-se o objetivo de descrever as etapas de criação do BZMAPS, realizar a análise acerca da forma de construção do banco de dados utilizado pelo aplicativo, e identificar as formas de análise das informações.

\section{MATERIAIS E MÉTODOS}

\subsection{Materiais}

Antes de segmentar os procedimentos metodológicos envolvidos nesse trabalho, há de citar os aplicativos os quais foram utilizados nas etapas metodológicas. Assim, deve-se explicitar a grande importância do Microsoft Office Visual Basic 6.0, utilizado concomitantemente a linguagem de programação Visual Basic, para realizar a construção do aplicativo BZMAPS.

Além disso, cabe ressaltar o uso do Microsoft Office Access, utilizado para inserir os dados mapeados. Ou seja, o mesmo foi o banco de dados utilizado para realizar a síntese das informações, as quais foram reportadas pelo BZMAPS.

Ainda, pode-se destacar que todo o mapeamento integral da área de estudo ocorreu com a utilização do aplicativo ArcGIS ${ }^{\circledR}$. Por meio dessa plataforma, realizouse o planejamento e a construção das bases de dados que dão subsídio aos dados inseridos no banco de dados.

\subsection{Métodos}

A fim de identificar os procedimentos teórico-práticos implementados nesse trabalho, os mesmos, a seguir, estarão endereçados cronologicamente.

Antes de ocorrer a inserção das informações no banco de dados, houve uma análise minuciosa quanto as informações que deveriam compor no escopo geral do banco de dados do aplicativo. Assim, para cada uma das construções (utilizando como critério de representação espacial o ponto), dispostas dentro da área suscetível 
do município de Jaguari, inseriram-se informações particulares referente a análise de risco à inundação. Dessa forma, totalizaram-se 401 residências.

Para cada um dos campos (construções), vários dados foram discretizados. Entre eles, citam-se: fotografia do imóvel, nome do bairro, informações cartográficas (latitude e longitude), informações intermediárias (classificação quanto a densidade de residências, acabamento da construção, tipo de construção, condição da construção, número de andares da construção) e informações finais acerca das inundações (classificação quanto a vulnerabilidade, ao perigo e ao risco).

Todas as informações (bases de dados), destacadas anteriormente foram organizadas no aplicativo ArcGIS ${ }^{\circledR}$, e, posteriormente, as mesmas foram inseridas no banco de dados utilizado. A inserção ocorreu de forma automática, a partir de um arquivo pré-organizado no formato "*.DBF". O arquivo *."DBF" gerado, posteriormente era convertido para o formato $M D B$, formato nativo do Access ${ }^{\circledR}$.

Posteriormente a análise particular de construção do banco dados, ocorreu a sistematização do BZMAPS. Assim sendo, salienta-se que o aplicativo engloba a análise de dados descritivos, além de realizar uma associação espacial, junto ao aplicativo Google Earth. Assim, pode-se destacar que há a análise dos dados em um banco de dados geocodificado, maximizando a qualidade das análises.

Desse modo, é possível realizar inúmeras análises acerca das residências localizadas dentro da área suscetível à inundação, através de uma interface amigável e simples, com disponibilização dos dados de forma ágil e fácil para qualquer usuário.

Além disso, no aplicativo, ao estruturá-lo com a linguagem Structured Query Language (SQL), as informações sintetizadas, tanto em campos textuais ou numéricos, podem ser selecionadas por meio de pesquisas pré-organizadas. Ainda, os dados finais, selecionados nas pesquisas, podem ser espacializados no Google Earth, por meio da geração de arquivos no formato Keyhole Markup Language (KML).

\section{DISCUSSÃO DOS RESULTADOS}

Após a aplicação do processo metodológico, com a análise e inserção das informações das construções, tem-se, por meio do aplicativo BZMAPS, a organização 
dos vários planos de informação sintetizados no banco de dados. Assim, a seguir, serão apresentadas as principais análises acerca do BZMAPS.

Inicialmente, na Figura 1, há a exposição da tela inicial do aplicativo, e na Figura

2 a apresentação da tela de consultas e de visualização dos dados.

Figura 1 - Tela inicial do aplicativo BZMAPS.

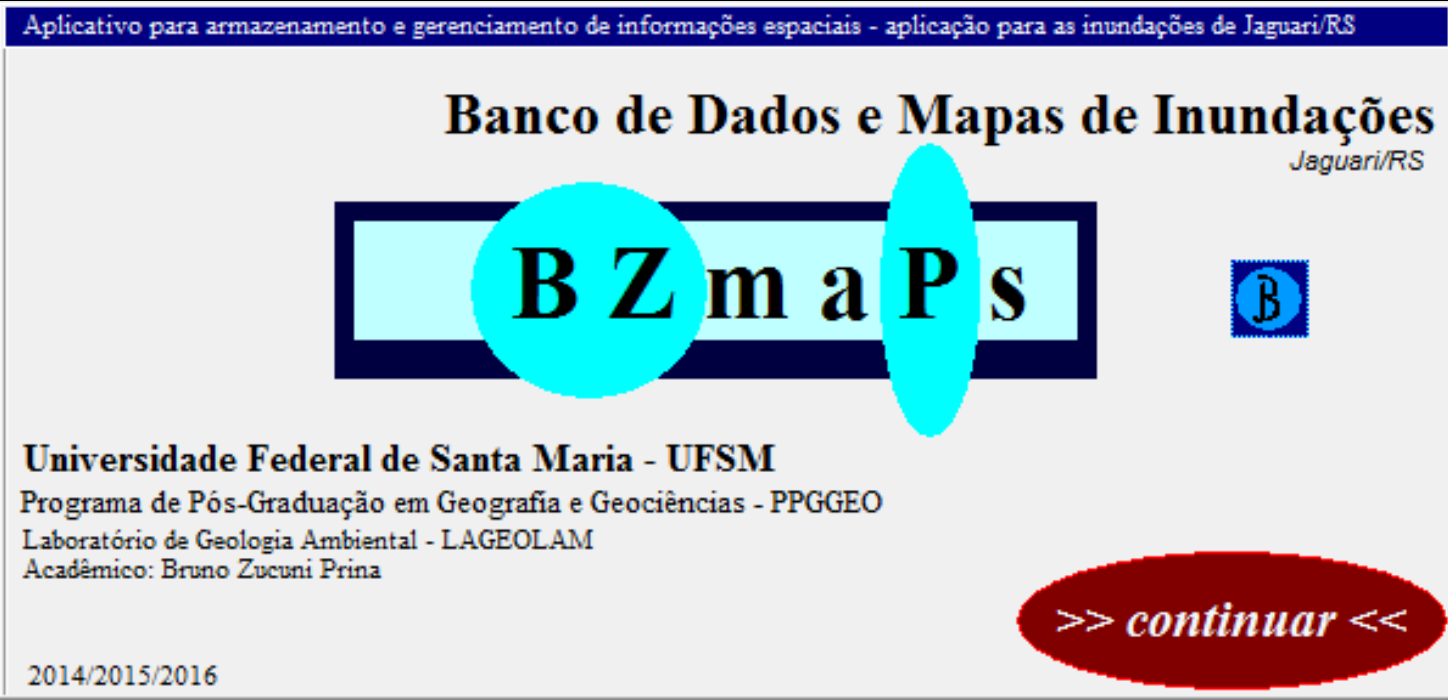

Figura 2 - Tela de consultas e de visualização de dados do aplicativo BZMAPS.

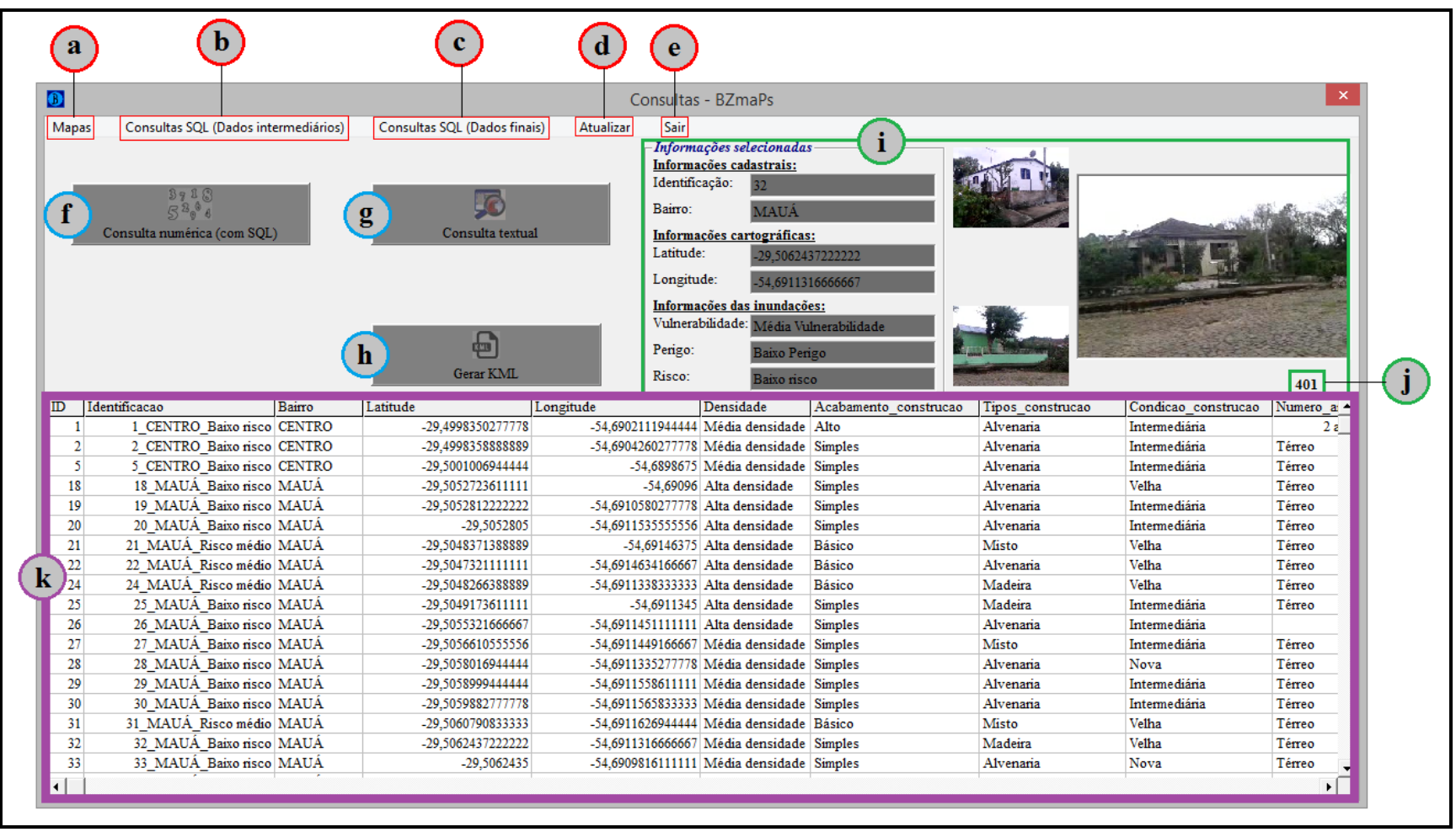


Junto a Figura 2 há a segmentação da tela de consultas do BZMAPS em 11 partes, denotados pela ordem das letras de "a" até "k". Sendo assim, a seguir, serão evidenciadas as particularidades de cada item.

"a": Nesse menu há a apresentação de cartografias pré-organizados em etapas anteriores, como por exemplo com o mapa de localização da área de estudo, de suscetibilidade, de perigo, de vulnerabilidade, de risco, de densidade de residências;

"b": Nesse menu há a organização de várias rotinas SQL, as quais apresentam resultados intermediários, com foco as variáveis analisadas para o mapeamento das áreas vulneráveis, ou seja, as características das residências.

"c": Nesse menu há a organização de rotinas SQL de dados finais, enfatizando os resultados obtidos, para cada residência, no mapeamento da vulnerabilidade, do perigo e do risco;

"d": Nesse menu é possível realizar a atualização da base de dados do banco de dados, ou seja, voltar a apresentação de todos os dados iniciais (sem apresentar dados de uma seleção por SQL);

"e": Menu para sair do aplicativo;

"f": Menu de consultas SQL numéricas;

"g": Menu de consultas SQL textual;

"h": Menu para geração de arquivos KMLs, a partir dos dados obtidos na implementação de uma seleção (pela estrutura SQL);

"i": Ao clicar em um registro (do ambiente "k") do banco de dados, nesse local haverá a busca de algumas informações cadastrais, cartográficas e sobre às inundações, além de identificar a fotografia da referida residência;

"j": Nesse local há a informação do número de dados dispostos no ambiente "k" (obtidos com a seleção dos dados);

"k": local que abrange todas as informações contidas no banco de dados, ou obtidas após a implementação de uma seleção de dados por SQL.

A fim de explicitar com mais detalhes os ambientes de consulta de dados, pela linguagem SQL, tem-se com as Figuras 3 e 4, a visualização das letras "f" e "g" (destacadas anteriormente na Figura 2), respectivamente. 
Figura 3 - Análise do ambiente de pesquisa SQL com dados numéricos.

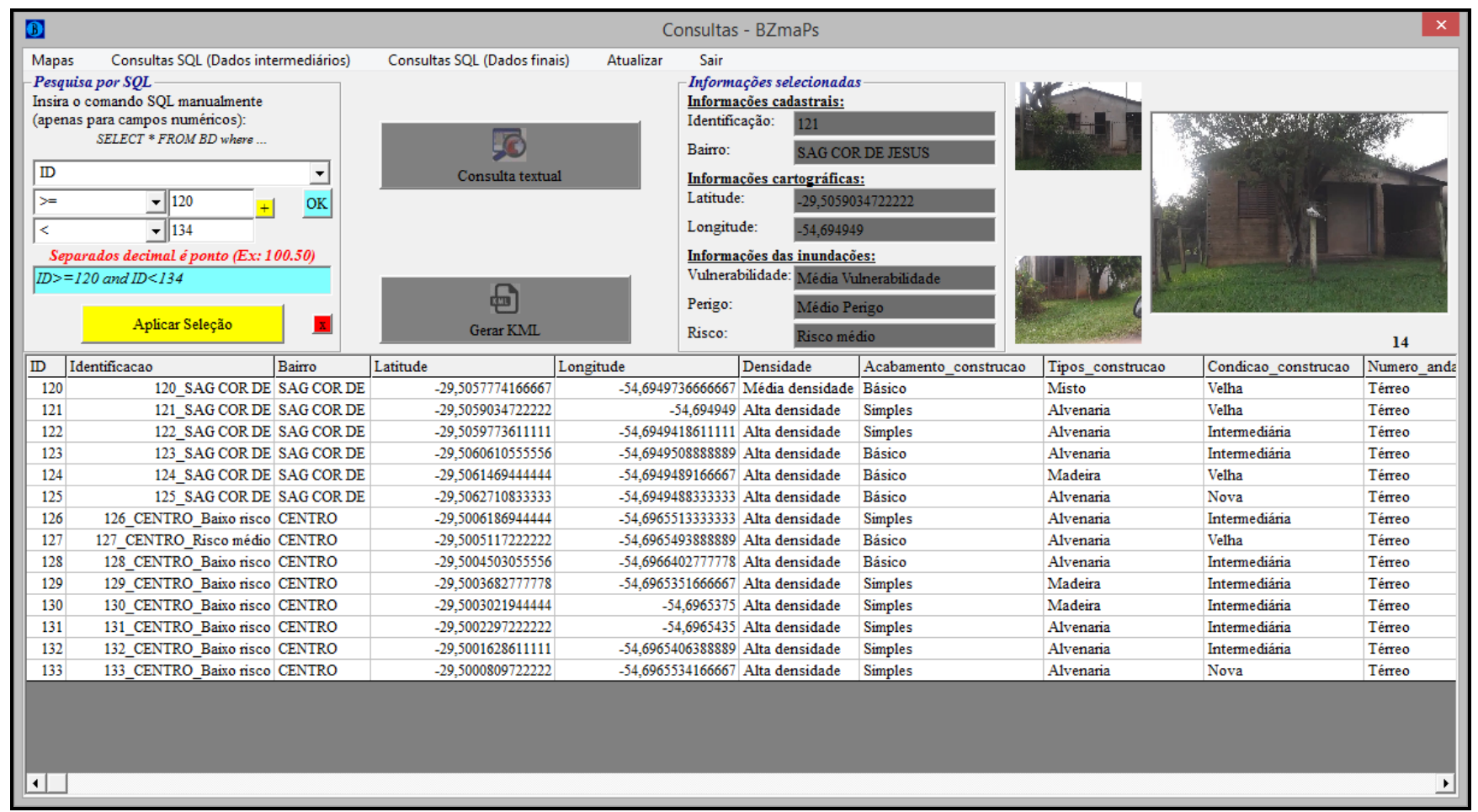

Figura 4 - Análise do ambiente de pesquisa SQL com dados textuais.

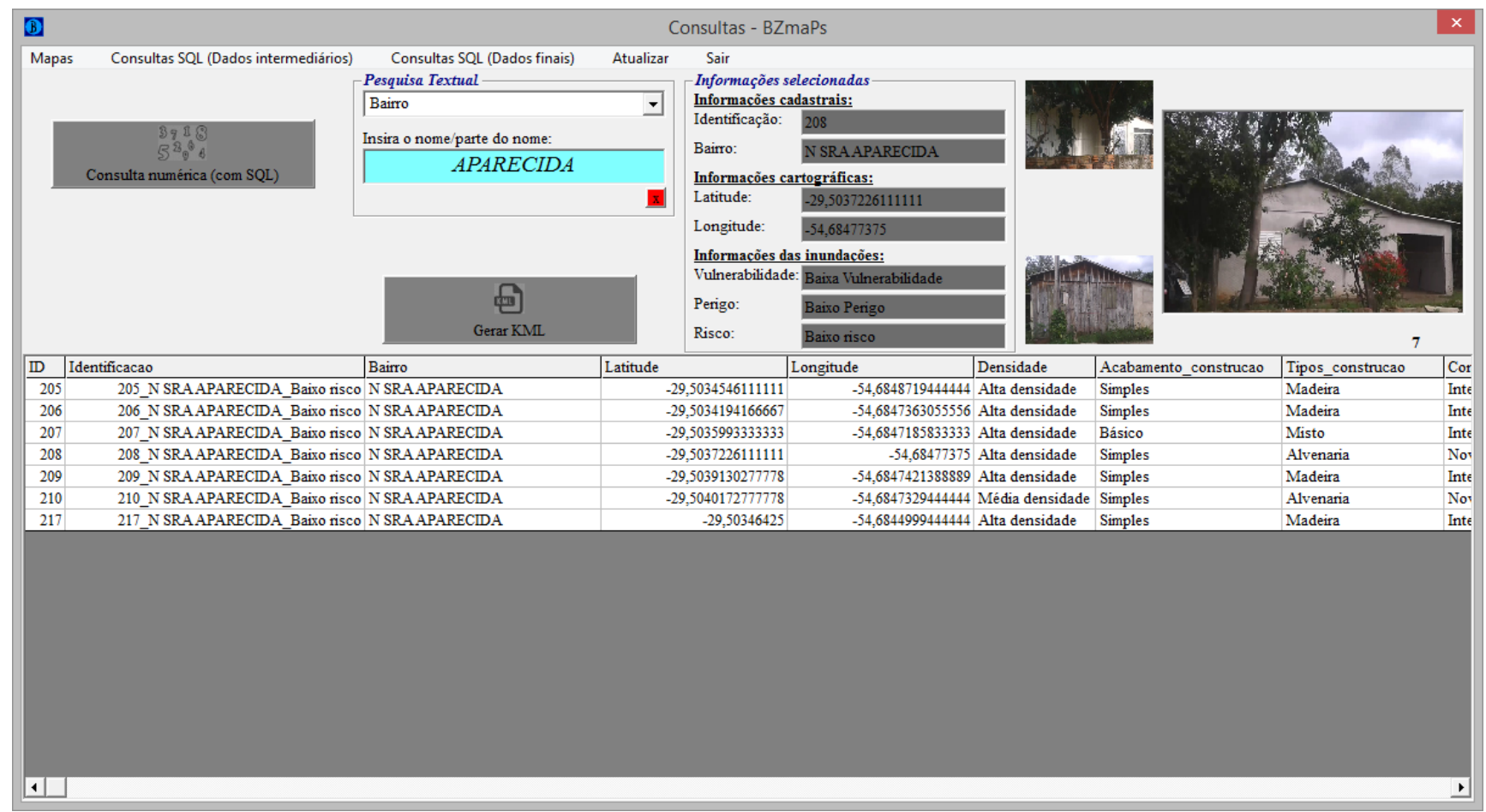

Com a análise da Figura 3, verifica-se que foi realizada uma pesquisa, através de um campo numérico, denominado "ID". Nesse local, foram selecionados todos os registros superiores ao número 120, e menores e iguais a 134. Assim, verifica-se que 
houve o registro de 14 itens ("j"), e, os mesmos foram selecionados no ambiente de amostra de dados ("k"). Dessa forma, todos os campos numéricos, poderão sofrer consultas conforme o modelo anterior.

Junto a Figura 4, pode-se verificar a estrutura de coleta de informações através de campos textuais, conforme o exemplo, para a tabela "Bairro", na qual foram selecionados todos os registros que continham a descrição "APARECIDA", a qual se remetia ao bairro "Nossa Senhora Aparecida". Nessa consulta, ao final, obteve-se 7 registros ("j"), e os dados selecionados estão destacados no ambiente tabular ("k"). Dessa forma, todas as pesquisas textuais poderão ser realizadas nesse ambiente.

Em linhas gerais, $o$ aplicativo subdivide-se em itens que podem ser manipulados por diferentes públicos. Ou seja, a implementação de rotinas préautomáticas de seleção dos dados ("b", "c") e rotinas a serem definidas pelo usuário ("f", "g") engloba o aplicativo em uma mesma versão, diferentes formas de realizar a coleta de informações.

Inicialmente, cabe ressaltar, que, para um público leigo, há os menus "b" e "c", no qual ocorre a consulta espacial (por SQL) com estruturas já determinadas. Ainda, com os dados selecionados, poderá haver a exportação das informações para o Google Earth, e assim, as informações descritivas, tornam-se georreferenciadas e, assim, mostram-se muito mais informativas, tornando-se uma informação geocodificada.

Um segundo público que pode dispor da análise dos dados, refere-se ao técnico, o qual possui um conhecimento pretérito acerca da linguagem SQL e de informática em geral. Assim, nos ambientes "f" e "g" pode haver a construção de estruturas SQL. Esse público, similar ao destacado anteriormente, pode exportar os dados para o Google Earth, e, assim, realizar outras análises espaciais de interesse do usuário.

A fim de exemplificar as análises que podem ser desenvolvidas dentro do aplicativo, a seguir, há um exemplo de aplicação dos dados. 
Inicialmente, por meio da área de consulta dos dados, no formato textual ("g"), pesquisaram-se as construções com o tipo de acabamento como "alto", "simples" e "básico", totalizando, respectivamente, 19, 303 e 79 residências ("j"). As referidas análises estão dispostas nas Figuras 5, 6 e 7.

Figura 5 - Pesquisa textual sobre o tipo de acabamento "alto" das construções.

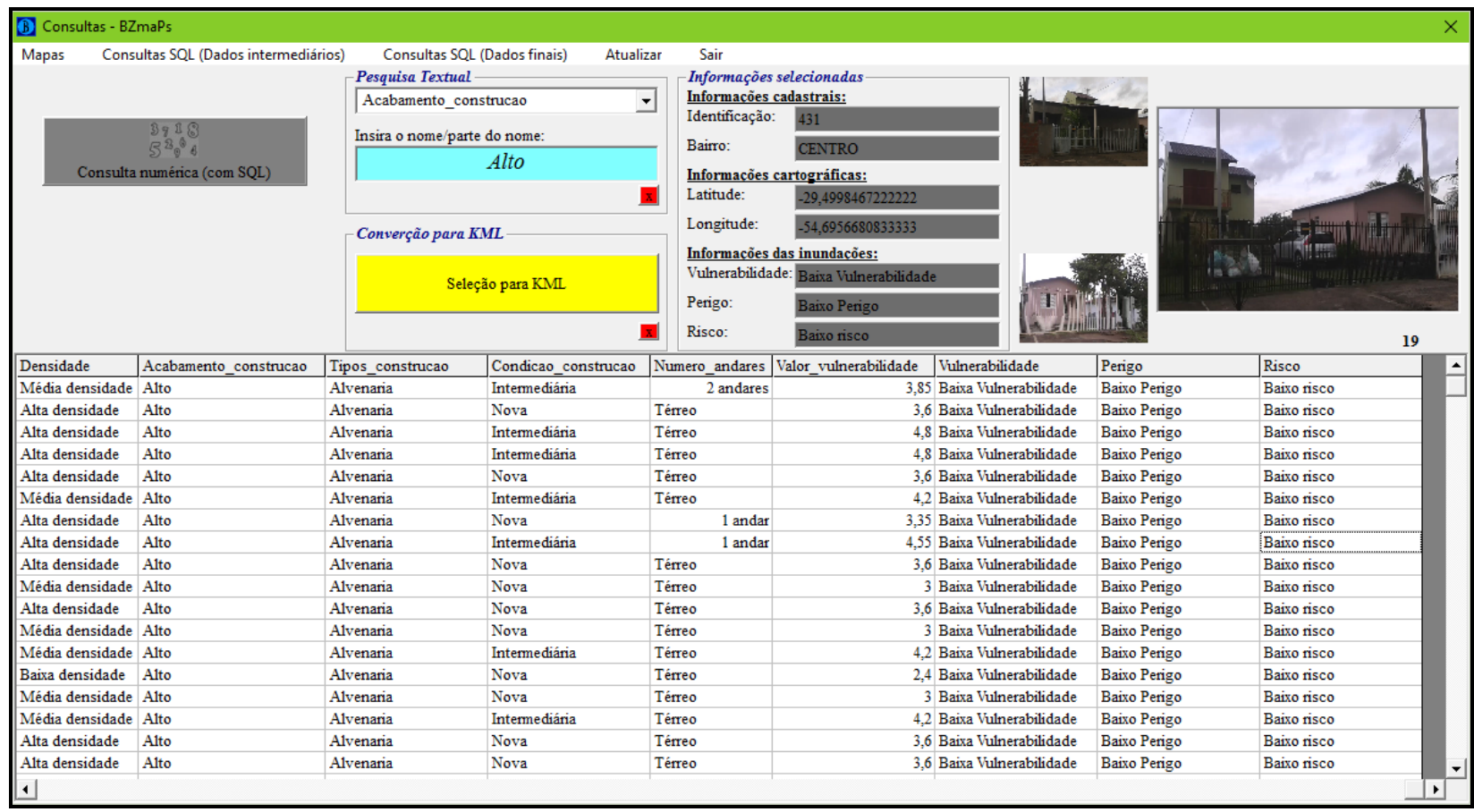

Figura 6 - Pesquisa textual sobre o tipo de acabamento "simples" das construções.

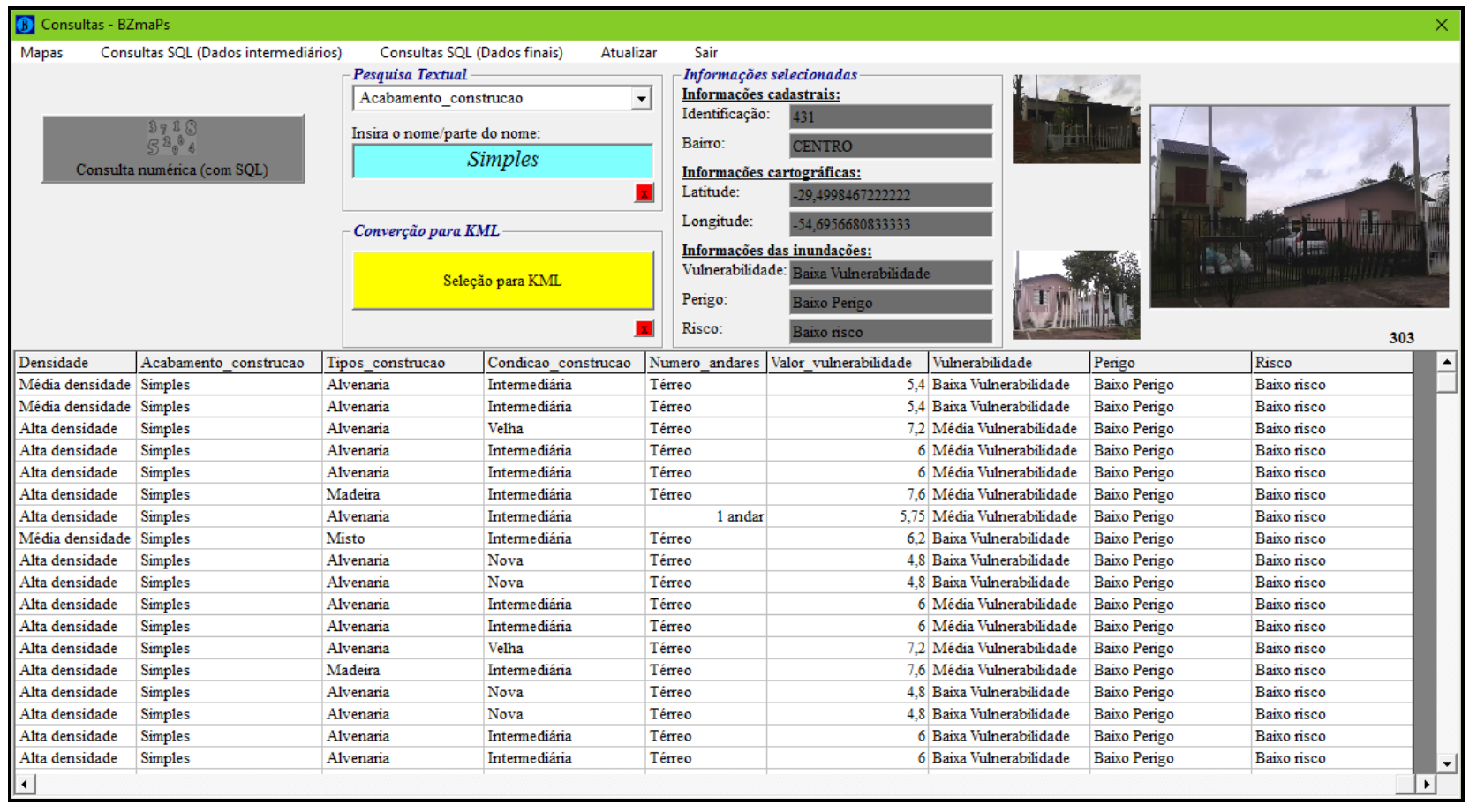


Figura 7 - Pesquisa textual sobre o tipo de acabamento "básico" das construções.

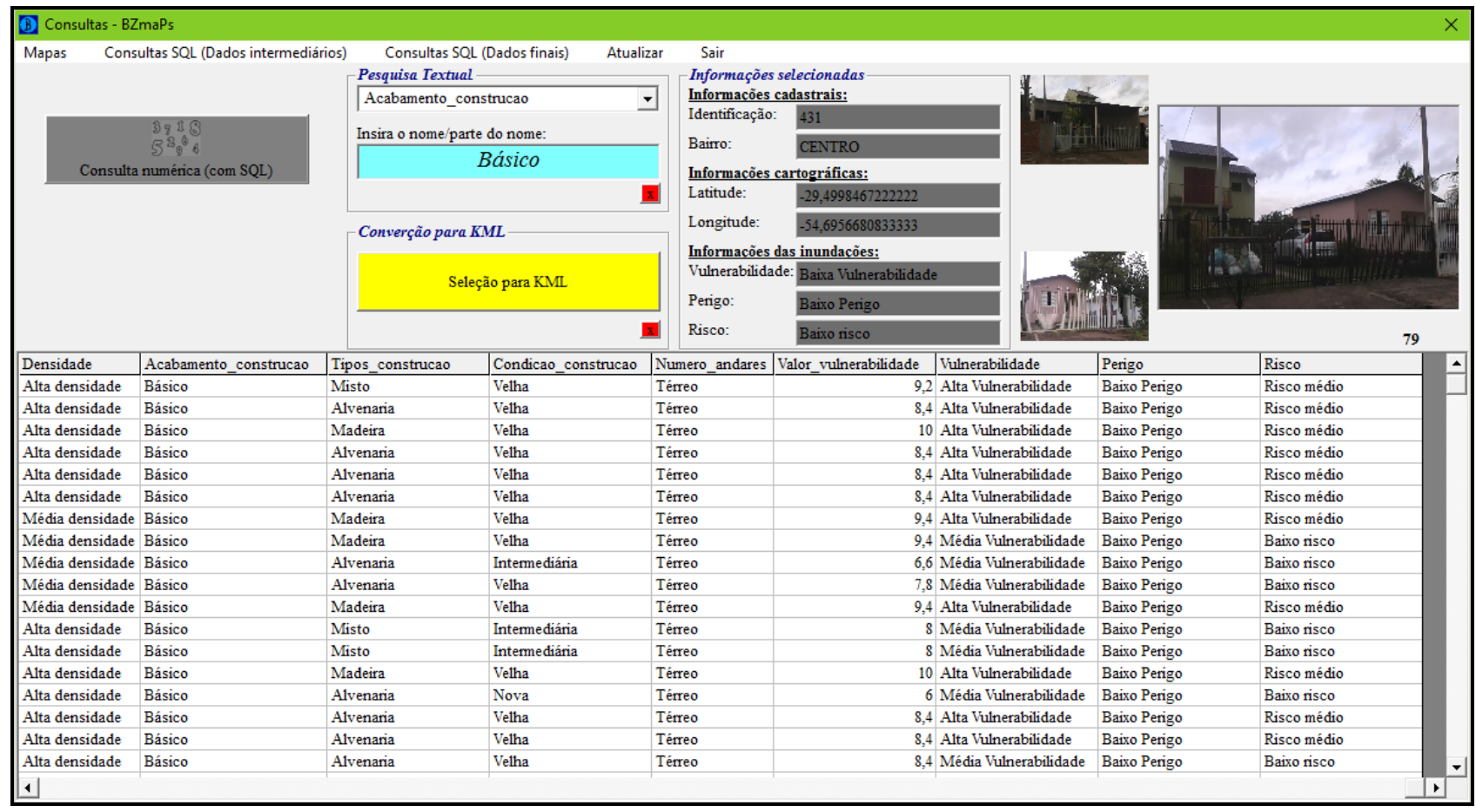

A partir das pesquisas analisadas anteriormente, os dados foram exportados para o Google Earth, conforme Figura 8.

Figura 8 - Análise dos dados por meio do Google Earth.

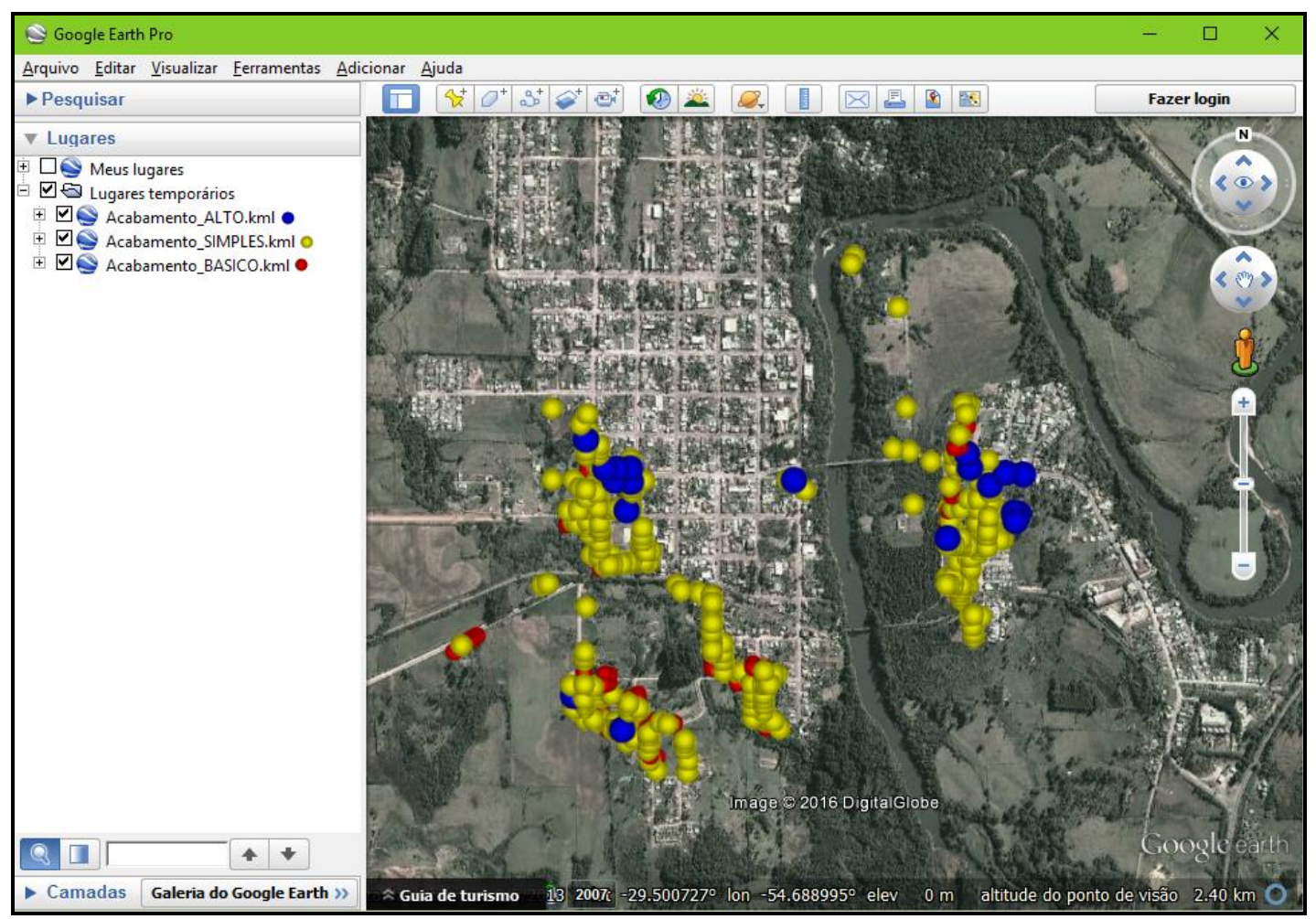

Ainda, os dados no formato KML podem ser analisados em aplicativos de SIG, como por exemplo, o ArcGIS ${ }^{\circledR}$, conforme retratado na Figura 9. 
Figura 9 - Análise dos dados por meio do ArcGIS ${ }^{\circledR}$.

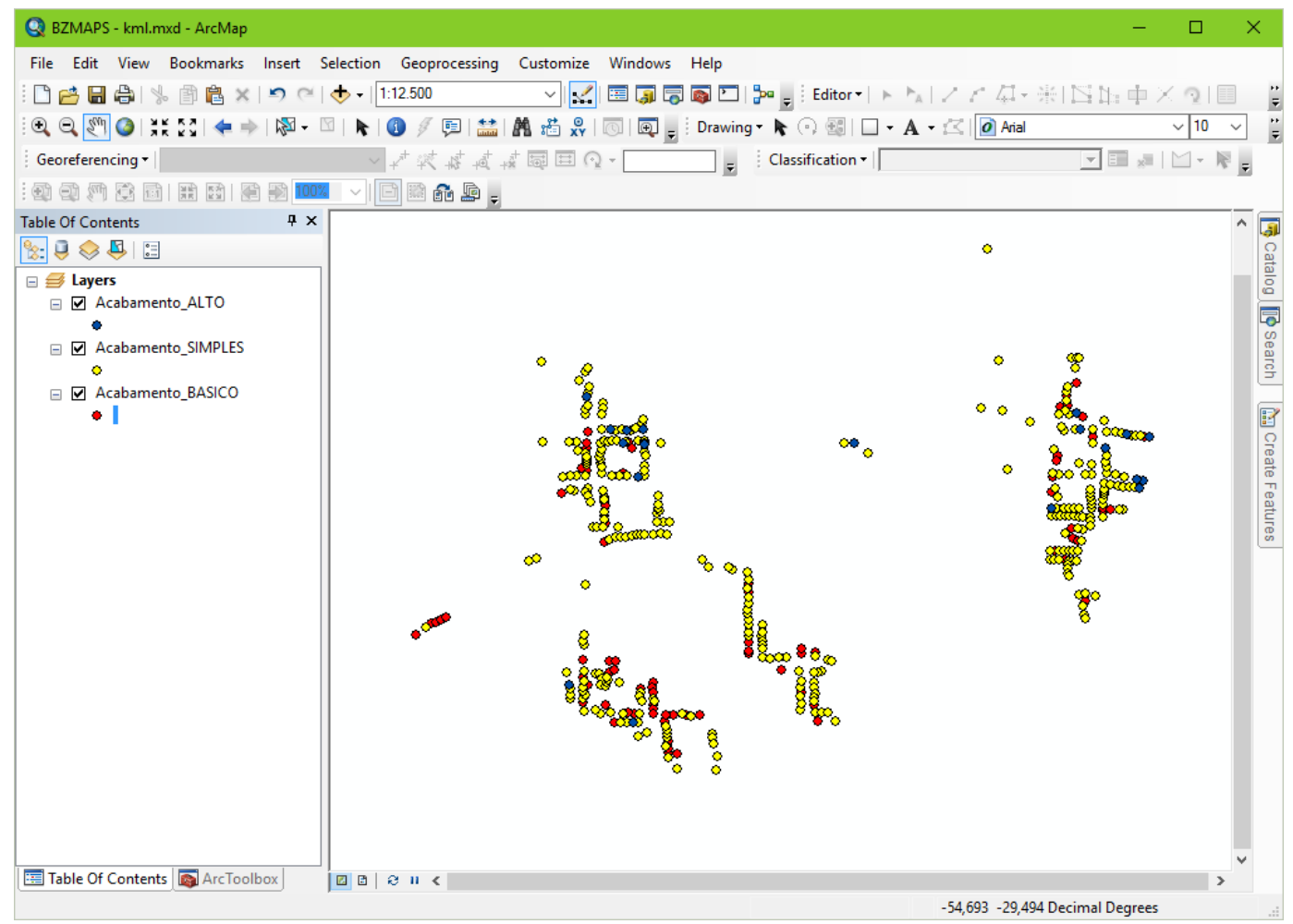

Assim, para finalizar, salienta-se que tanto o público leigo ou técnico poderá desfrutar da análise dos dados, bastando, realizar o planejamento e organização dos dados de entrada.

\section{CONSIDERAÇÕES FINAIS}

Considera-se de extrema importância ao trabalho as metodologias envolventes para sistematização dos dados. As mesmas mostraram-se inteiramente ideais para a construção de uma base de dados sólida e eficiente para a análise de dados ligados a análise de riscos à inundação.

Conclui-se, de forma geral, que o desenvolvimento do aplicativo BZMAPS mostrou-se inteiramente operacional para trabalhar dentro da temática do presente trabalho, as inundações. Assim, não obstante haver a construção das bases cartográficas, com o BZMAPS é possível disponibilizar os dados de forma clara e organizada, facilitando inclusive, a utilização desses, dentro de órgãos públicos, como as prefeituras. 
Além disso, uma etapa de extrema importância dentro da análise de riscos à inundação é gerar a síntese dos dados, e, dessa forma, objetivar as informações de um determinado mapeamento. Assim sendo, verifica-se que com a organização dos dados, junto ao aplicativo BZMAPS, é possível obter a síntese dos dados cadastrados, auxiliando, inclusive, a esfera pública, a qual poderá analisar e utilizar os dados mapeados.

\section{REFERÊNCIAS BIBLIOGRÁFICAS}

AYALA-CARCEDO, F. J. La ordenación del teritorio en la prevención de catástrofes naturales y tecnológicas. Bases para un procedimiento técnico-administrativo de evaluación de riesgos para la población. Boletín de la A.G.E. $n^{\circ} 30,2000$, p. 37-49, Instituto Geológico Y Minero de España.

CASTRO, S. D. A. de. Riesgos y peligros: una visión desde la Geografía. Scripta Nova, Revista Electrónica de Geografía y Ciencias Sociales. Universidad de Barcelona, ISSN 11389788, n 60, 15 de marzo de 2000, 15 p.

$\mathrm{KRON}, \mathrm{W}$. Keynote lecture: flood risk = hazard $\mathbf{x}$ exposure $\mathbf{x}$ vulnerability. Flood Defence 2002, Wu et al. (eds) (C) 2002 Science Press, New York Ltd., ISBN 7-03-008310-5.

MAGNANELLI, N. P. Perigo x Risco. São José dos Campos, 2012. Disponível em: <http://www.cvs.saude.sp.gov.br/up/7\%20-\%20Conceito\%20Risco\%20X\%20Perigo\%20\%20Neli\%20Pieres\%20Magnanelli\%20(DVST).pdf >. Acesso em 24 ago.2013.

RIBEIRO, C. B. de M.; LIMA, R. N. de S. Simulação de inundações urbanas a partir da integração de técnicas de geoprocessamento à modelagem hidráulica e hidrológica. Revista de Geografia - PPGEO - v. 2, nº 1, p.1-9, 2011.

SANTOS, R. F. dos (org). Vulnerabilidade Ambiental: desastres naturais ou fenômenos induzidos? Brasília: Ministério do Meio Ambiente, 2007. 